\title{
Biogeografias: diálogo entre obra e vida de Clarice Lispector e Caio Fernando Abreu
}

\author{
Biogeografias: el diálogo entre el trabajo y la vida de Clarice Lispector y \\ Caio Fernando Abreu
}

\author{
Biogeographies: dialogue between work and life of Clarice Lispector and \\ Caio Fernando Abreu
}

\author{
Milena Nolasco Marques Silva ${ }^{1}$ \\ Edgar Cézar Nolasco²
}

\begin{abstract}
Resumo
O assunto desenvolvido aqui está diretamente relacionado a criação de uma amizade metafórica por intermédio de dois escritores Caio Fernando Abreu e Clarice Lispector, enfatizando a relevância de não serem especificamente amigos, uma vez que somente se viram em uma noite de autógrafos em uma livraria. Todavia, o ponto de partida para tal aproximação dá-se por uma abertura nas obras de Caio Fernando que se volta para características intrínsecas às de Clarice e a discussão proposta visa propor uma conceituação teórica e crítica que amplie a compreensão do lócus fronteiriço em relação das biogeografias diferentes. Também há ocorrências de algumas epigrafes de Lispector nas obras do escritor gaúcho. Por meio disso, pressupõe-se Lispector como precursora de Abreu, levando-se em conta o viés da crítica biográfica fronteiriça. Por fim com efetivação desta amizade pelo lócus literário, mais a inscrição da presença de uma paisagem do bios, propõe-se a uma discussão crítico-biográfica fronteiriça que sustentará toda a proposta de trabalho.
\end{abstract}

Palavras-Chave: Amizade; Crítica biográfica fronteiriça; Literatura e Paisagem.

\section{Resumen}

El tema desarrollado aquí está directamente relacionada con la creación de una amistad metafórica a través de dos escritores Caio Fernando Abreu y Clarice Lispector, haciendo hincapié en la importancia de no ser específicamente amigos, ya que sólo se ve en una firma de libros en una librería. Sin embargo, el punto de partida para un enfoque de este tipo se lleva a cabo a través de una abertura en la obra de Caio Fernando que convierte a las características intrínsecas a Clarice y la propuesta de debate tiene por objeto proponer una conceptualización teórica y crítica para ampliar la comprensión del locus relativa de frontera biogeografias diferente. También hay casos de algunos epígrafes de Lispector en las obras del escritor gaucho. Por esto, se supone Lispector como precursor Abreu, teniendo en cuenta el sesgo de la crítica biográfica fronteriza. Por último, con la realización de esta amistad por el locus literaria más el registro de la presencia de un paisaje bios, se propone una frontera debate crítico-biográfico que soportará todo el trabajo propuesto.

Palabras claves: Amistad; biográfica fronteriza crítica; Literatura y paisaje.

\section{Abstract}

The subject developed here is directly related to the creation of a metaphorical friendship through two writers Caio Fernando Abreu and Clarice Lispector, emphasizing the relevance of not being specifically friends, since they only saw one night of autographs in a bookstore. However, the starting point for such an approach is an opening in the works of Caio Fernando that turns to characteristics intrinsic to those of Clarice and the proposed discussion aims to propose a theoretical and critical conceptualization that broadens the understanding of the border locus in

${ }^{1}$ Graduanda do curo de Letras da Universidade Federal de Mato Grosso do Sul- UFMS; Campo Grande; Mato Grosso do Sul; Brasil; milena jesus30@hotmail.com.Trabalho apresentado no I Seminário Latino-Americano de Estudos em Cultura - SEMLACult, Foz do Iguaçu/PR, Brasil, 2017.

${ }^{2}$ Professor Doutor, da Universidade Federal de Mato Grosso do Sul- UFMS e Coordenador do Grupo de pesquisa Núcleo de Estudos Culturais Comparados- NECC- CNPq/UFMS; Campo Grande; Mato Grosso do Sul; Brasil; ecnolasco@uol.com.br. Trabalho apresentado no I Seminário Latino-Americano de Estudos em Cultura -

SEMLACult, Foz do Iguaçu/PR, Brasil, 2017. 
relation to the Different biogeographies. Also there are occurrences of some epigraphs of Lispector in the works of the Caio writer. Through this, Lispector is presumed as precursor of Abreu, taking into account the bias of the biographical criticism frontier. Finally, with the effect of this friendship through the literary locus, plus the inscription of the presence of a landscape of the bios, it is proposed to a critical-biographical frontier discussion that will sustain the whole proposal of work.

Keywords: Friendship; Frontier biographical criticism; Literature and Landscape.

\section{Introdução}

A proposta basilar do presente trabalho resume-se na discussão da relação entre os escritores Clarice Lispector e Caio Fernando Abreu, falando da amizade, biogeografias, obra e vida dos escritores, que ultrapassam todo e qualquer limite linguístico e literário. As relações estabelecidas por Caio e Clarice vão além das fronteiras, alcançando dimensões biográficas e culturais, ao levar em consideração o que a figura de um escritor representa para o outro, como afirma Eneida Maria de Souza (2002), e os performáticos que concretizam todo sujeito nos espaços públicos e privados. Nesse sentido, o objetivo desta seção é mostrar como a crítica biográfica trabalha a relação entre escritores a partir do estabelecimento e criação de amizades metafórico-literárias.

\section{Diálogo entre os escritores Clarice Lispector e Caio Fernando Abreu: amizade e biogeografias}

Nesse sentido, o objetivo desta pesquisa é mostrar como a Crítica Biográfica Fronteiriça trabalha a relação entre os escritores a partir do estabelecimento e criação de amizades metafórico-literárias. Assim, estabelecer relações discursivas entre a obra, a cultura e o bios tanto de Caio e Clarice envolvidos na cena discursiva quanto do crítico leitor ao inserir-se como sujeitos participantes da atualização empreendida pelo ato da leitura e como ator do exercício crítico.

A amizade entre dois escritores literários Caio Fernando Abreu e Clarice Lispector, tendo alguns conceitos da crítica biográfica contemporânea como norteadora da nossa pesquisa. Partimos da proposição da natureza compósita da crítica biográfica ao relacionar as vidas e as obras desses escritores ao levar em consideração as pontes metafóricas que estabeleceremos a partir da amizade entre os dois autores, entre essas duas instâncias, tanto o que é tido como fato, documento, arquivo quanto aquilo que é ficcional, as obras literárias. Assim, partiremos do que afirma Eneida Maria de Souza sobre a abertura do campo da cultura e sobre a natureza diversa da crítica biográfica ao considerar que:

\footnotetext{
Diante da abertura teórica instaurada pelas abordagens contemporâneas, os limites entre os territórios disciplinares são enfraquecidos, provocando o questionamento dos lugares produtores de saber, assim como dos conceitos operatórios responsáveis pela produção de paradigmas e de metodologias críticas. A crítica biográfica, por sua natureza compósita, englobando a relação complexa entre obra e autor, possibilita a interpretação da literatura além de seus limites intrínsecos e exclusivos, por meio da construção de pontes metafóricas entre o fato e a ficção. (SOUZA, 2002, p.105)
} 
Desse modo, Caio Fernando Abreu, que incita este campo metafórico da amizade, através de um acontecimento, depara-se com Clarice Lispector em uma noite de autógrafo. A partir deste encontro relatado em cartas, Abreu sentiu de súbito uma intensa admiração por Lispector. Após este fato ocorrido, Caio Fernando Abreu estipula um diálogo com as obras de Clarice Lispector, ao dedicar-lhe inúmeras epigrafes claricianas em suas obras, e alguns títulos tais como: O ovo apunhalado e As frangas, que iludem a alusão ao conto de Clarice Lispector, "O ovo e a galinha."

Em síntese, para retomar a noção de amizade por nós cunhada no início, Caio Fernando Abreu avança as desigualdades sociais por meio da literatura em relação à Clarice Lispector. Gesto que, entretanto, não configura a lógica binarista de que a literatura de Caio não dialoga mais com a literatura clariciana. Pelo contrário, visto que, segundo Francisco Ortega,

\begin{abstract}
A amizade assim concebida estaria aberta para o acontecimento, para o novo, para a invenção e para a experimentação. Seria uma amizade instável, dinâmica, com relação à definição dos valores. [...] Talvez um dia aprendamos a conviver com a imagem de um amigo que não aparece como nossa imagem especular, mas como algo radicalmente diferente e sejamos capazes de aceitar essa distância, essa diferença como condição da amizade. (ORTEGA, 2000, p. 83-84).
\end{abstract}

Ademais, trabalhamos com a ligação da vida literária com a civil dos escritores, mais estritamente, a relação entre suas produções ficcionais e o ofício de jornalista que exerceram durante a década de 1970, fato que corroborou alguns encontros entre os dois. Sobre essa perspectiva adotada, podemos observar também a relação entre os escritores brasileiros com a cultura de massa e os movimentos políticos que emergiram na ditadura militar brasileira.

Nessa perspectiva, tomemos como exemplo a relação que a epígrafe pode possuir com o texto anterior, quando o trecho escolhido é deslocado e revitalizado na obra em que é reinserido. Mais do que isso, observemos como esse simples deslocamento, como chamariam os modernos, nada tem de simples. Mas sim carrega consigo fortes relações metafóricas e interdiscursivas com a política e os discursos anteriores que a precede, bem como os contemporâneos. 
Além da questão de estudar os intelectuais Clarice Lispector e Caio Fernando Abreu, ao relacionar obra e vida, unindo bios e lócus dos escritores, tendo o arcabouço teórico da crítica biográfica e pós-colonialidade. Se partirmos da obra de Caio Fernando Abreu, podemos identificar logo de início a dedicatória e epígrafe que está explícita no livro As Frangas e, com isso, é possível visualizar que a obra A vida íntima de Laura está ligada à existência de As Frangas.

A infância dos dois escritores que remetem ao gosto deles por galinhas/frangas, havendo, portanto, mais um fator extrínseco, uma ligação entre a vida dos escritores, que converge para as duas obras. Em As Frangas, por exemplo, ao relatar as brincadeiras com os irmãos no pátio da casa dos seus pais, Caio afirma "A gente sempre parava de brincar ali por perto do galinheiro mesmo. Por isso também a gente olhava tanto as galinhas" (ABREU, 2001, p. 13). Em A vida íntima de Laura, o trecho que dialoga com o de Caio é "Quando eu era do tamanho de você, ficava horas e horas olhando para as galinhas. Não sei por quê. Conheço tanto as galinhas que podia nunca mais parar de contar” (LISPECTOR, 1999, p. 21). Esta afirmação remete a outra encontrada no final do livro de Abreu, que é quando ele reitera que, na infância, de tanto brincar próximo àquele galinheiro, acabou conhecendo a intimidade das frangas.

O diálogo se estabelece a partir do conceito de biogeografias (bio+geografia) de BESSA(2016), que aborda "as noções de espaços e sujeitos, produções, práticas e culturas que inserem no biosistema", mas estão os escritores mais na ordem da biografia cultural como também de suas relações de pertencimento dos mais "diferentes lugares e das suas identidades culturais". Cada bios é único nas suas especificidades biográficas, sociais, culturais e geográficas. Os diálogos entre os escritores estão intrínsecos ao bios e aos lugares enunciativos dos sujeitos. Esse conceito de biogeografia, segundo BESSA, parte da "premissa da crítica biográfica em relação a sua natureza compósita “ (SOUZA,2002). Por consequência, a crítica biográfica e a teoria pós-colonial dão "respaldo epistêmico suficiente ao eleger os espaços geográficos como lugares enunciativos particulares ", (MIGNOLO, 2003).

Assim, por haver esse diálogo entre as obras de Caio Fernando Abreu e Clarice Lispector, a discussão se deterá nessa relação metafórica. Com a pesquisa apresentada e as questões teóricas acerca dos temas apresentados anteriormente, estabeleceremos como plano de fundo a Paisagem por agregar essas "múltiplas memórias" (ACHUGAR, 2006, p.60) que "supõe[m] um posicionamento e um lugar específico a partir de onde se fala e a partir de onde se lê" (ACHUGAR, 2006, p.60) inseridos nas paisagens escriturais que "acompanham as 
mudanças históricas, políticas e culturais do lugar. " E posicionando a paisagem ao entrelugar, conforme Lopes apresenta "O entre-lugar é o ponto de partida de estudo das paisagens transculturais, capaz de propor tanto uma leitura estética quando cultural de obras artísticas, produtos culturais e processo sociais. " (LOPES, 2012, p.21). Como a proposta do Núcleo de Estudos Culturais Comparados - NECC, do qual faço parte, é voltada a fazer uma leitura a partir do lócus de onde falamos.

Por fim, na década de 1990, Caio Fernando Abreu repete o gesto de Clarice Lispector, ao argumentar em defesa da publicação de livros memorialísticos e com fragmentos: "Mas jamais o assumiria se, como às minhas outras ovelhas brancas publicadas, não fosse eu capaz de defendê-lo com unhas dentes contra os lobos maus do bom-gostismo instituído e estéril”. (ABREU, 2013, p. 6). Portanto, a epígrafe clariciana na obra de Abreu não possui somente função introdutória, que sintetiza a temática da obra, mas, antes de tudo, suscita discussões sobre a própria literatura, a plêiade de escritores imbricados na relação discursiva presente no trecho e, sobretudo, a presença de duas recepções de diferentes gerações (década de 1960/70 e de 1990). Findada a discussão teórico/crítica por nós detalhada neste item do trabalho, cabe-nos mostrar as conclusões a que chegamos ao realizar as leituras e ao estudar a amizade entre Caio Fernando Abreu e Clarice Lispector.

A noção política e social de amizade que conjecturávamos sob feição hipotética foi confirmada em se tratando da relação entre Caio Fernando Abreu e Clarice Lispector no plano biográfico e ficcional, como mostramos no tópico anterior e neste texto como um todo. No interior dos comentários de leitores apreciadores da literatura dos contistas, prevalece a ideia de que o escritor gaúcho repetiu à exaustão a fórmula da ficção da escritora, ideia esta que contestamos por meio do caminho crítico trilhado durante o desenvolver do trabalho.

Não só nos afastamos do senso comum, como dos pressupostos da crítica literária moderna e da tradição filosófica ocidental, pois, a noção de amizade aqui cunhada segue a 
diretriz do que afirma Francisco Ortega: “[...] ao contrário de Aristóteles e da tradição, a amizade não fortalece a identidade, mas constitui antes a possibilidade de nos transformarmos, a amizade é, no fundo, uma ascese, isto é, uma atividade de autotransformação e aperfeiçoamento". (ORTEGA, 2000, p. 80-81).

Falar de amizade em vez de signos que denotam conceitos fraternalistas veta a possibilidade de o discurso crítico estabelecer relações hierárquicas entre escritores. Por exemplo, a visada historiográfica que determina Clarice Lispector e Lúcio Cardoso como escritores-pais de Caio Fernando Abreu e a geração de literatos da década de 1970. Dessa forma, a amizade entre os escritores estipulados aqui segue também a diretriz do que afirma Eneida Maria de Souza acerca da citação, haja vista o considerável número de citações e epígrafes de Lispector que Abreu realizou em suas produções:

\footnotetext{
Citar é reescrever os empréstimos, reverenciar os mestres e, principalmente, reconsiderar o resíduo que ficou de determinado autor ou o que posteriormente foi percebido. O gesto de citar o outro desvincula-se do processo reativador de influências, por se entender que a transmissão de saberes se efetua por um sistema de trocas e doações. (SOUZA, 2007, p.37).
}

A discussão da estudiosa mineira contribui para atualizar teoricamente a noção de influência, visto que o uso da metáfora familiar para estabelecer relações entre literatos já é uma prática ultrapassada nos estudos literários, sendo a influência um processo pelo qual valores e características são renovados, e não preservados, na escritura do escritor contemporâneo por meio de "um sistema de trocas e doações" preponderando a leitura do presente; como bem defendeu o narrador de "Pierre Menard, autor do Quixote", ao advogar que o Quixote do simbolista francês do século XX é mais rico que o de Cervantes do século XVII, por estar situado no presente, enriquecido com a evolução por que o mundo passou em quase quatrocentos anos.

Além da teorização de Eneida acerca da citação e revitalização da noção de influência que a estudiosa mineira realiza, contamos com o ensaio "Kafka e seus precursores", de Jorge Luis Borges, para desmistificar a noção de influência estancada no discurso dos leitores experimentais e da crítica literária moderna, pois, como afirma o escritor argentino,

Ao vocabulário crítico, a palavra precursor é indispensável, mas indispensável também é tentar purificá-la de toda conotação polêmica ou de rivalidade. O fato é que cada escritor cria seus precursores. Seu trabalho modifica nossa concepção do passado, como há de modificar o futuro. Em nada importa, nesta correlação, a identidade ou a pluralidade dos homens. (BORGES, 2017, s/p.).

Por fim, a partir do nosso trabalho, emerge a reconsideração teórica de que a relação entre textos literários se encontra sob a metáfora do mosaico, onde é possível o escritor contemporâneo "reconsiderar o resíduo" através da leitura do presente, aproximando seu 
texto dos anteriores, fora da conotação de influência passiva e de verticalidade, na qual o objeto anterior encontra-se numa posição sublime ante os posteriores. Válida ainda é a "transmissão de saberes efetuada por um sistema de trocas e doações" que se inscreve numa relação ideológica e de amizade, considerando a lição borgiana acerca dos precursores, que versa a desconstrução do sentido paternalista residente na palavra "precursor".

Logo, as relações entre vida, obra e geografias são criadas a partir da relação metafórica existente entre obra e vida. As biografias são sempre abertas e inconclusas. A crítica biográfica fronteiriça nos possibilita a liberdade para realizar outras leituras, outros olhares, além de permitir a construção de vinculações culturais. Portanto, a crítica biográfica fronteiriça e pós-colonial, segundo Edgar Cézar Nolasco (2015), nos dá o direito de sugestões de leituras que dão continuidade à nossa discussão.

\section{Referências}

ABREU, Caio Fernando. As Frangas. SÃo Paulo: Editora Globo, 2001. , Caio Fernando. Ovelhas negras. Porto Alegre: Editora L\&PM, 2013.

ACHUGAR, Hugo. Planetas SEM Boca: ESCRitos efÊMeros SObre ARTe, CUltura E Literatura. TRAD. DE LySlei NASCIMENTO. Belo HorizONTE: EditORA UFMG, 2006.

BESSA, Marcos ANTÔNIO O. BIOGEOGRAFIAS OCIDENTAIS/ORIENTAIS: (I)MIGRAÇÕES DO BIOS E DAS EPISTEMOLOGIAS ARTÍSTICAS NO FRONT. IN: CADERNOS DE ESTUDOS CULTURAIS: OCIDENTE/ORIENTE: MIGRAÇÕES. V. 8, N. 15. CAMPO GRANDE: EdITORA UFMS, 2016. P. 47-66.

BORGES, Jorge Luis. Pierre Menard, autor do Quixote. In: BORGES, Jorge Luis. Ficções. Trad. Davi Arrigucci Jr. São Paulo: Companhia das Letras, 2007.

Jorge Luis. Kafka e seus precursores. Disponível em: http://nopasseiointimo.blogspot.com.br/2014/07/traducao-kafka-e-seus-precursores- de.html. Acesso em: 21 de julho de 2017.

LISPECTOR, ClARICE. A VIDA ÍNTIMA DE LAURA. Rio DE JANEIRO: RoCCO, 1999.

LOPES, DENÍLSON. A DELICADEZA: ESTÉTICA EXPERIÊNCIA E PAISAGENS. BRASÍLIA: EDITORA UNB, 2007. 
LOPES, DENÍLSON. NOTAS SOBRE CRÍTICA E PAISAGENS TRANSCULTURAIS. IN: CADERNOS DE ESTUDOS CULTURAIS: CRÍTICA CONTEMPORÂNEA. CAMPO GRANDE, MS: EDITORA UFMS, V.2, N.3, P.1-155, JAN. /JUN. 2010 P.21-28.

LOPES, DENÍlSON. NO CORAÇÃO DO MUNDO. RiO DE JANEIRO: ROCCO, 2012.

MignOlo, Walter. Histórias Locais/ Projetos globais: COlOnialidade, SABeres Subalternos E PENSAMENTO Liminar. TRAD. SOlAnge Ribeiro DE Oliveira. Belo HORIZONTE: EDITORA UFMG, 2003.

NOLASCO. EDGAR C. CRÍTICA BIOGRÁFICA FRONTEIRIÇA (BRASIL/PARAGUAI/BOLÍVIA). IN: CADERNOS DE ESTUDOS CULTURAIS: BRASIL/PARAGUAI/BOLÍVIA. V. 7, N. 14. CAMPO GRANDE: EDITORA UFMS, 2015, P. 47-63.

ORTEGA, Francisco. Para uma política da amizade: Arendt, Derrida, Foucault. Rio de Janeiro: Relume Dumará, 2000.

SOUZA, Eneida Maria De. CRítica CUlt. Belo Horizonte: Editora UFMG, 2002.

SOUZA, ENEIDA MARIA DE. NOTAS SOBRE A CRÍTICA BIOGRÁFICA. IN: CRÍTICA CULT. BELO HORIZONTE: EDITORA UFMG, 2002.

2007. , Eneida Maria de. Tempo de pós-crítica. Belo Horizonte: Veredas \& Cenários, 